\title{
Exercise prescription for weight management
}

\author{
Andrew P. Hills* and Nuala M. Byrne \\ School of Human Movement Studies, Queensland University of Technology, Victoria Park Road, Kelvin Grove 4059, \\ Brisbane, Queensland, Australia
}

Whilst short-term weight loss is readily achievable, acceptable treatment regimens for long-term maintenance are less commonplace. The limited success in long-term weight-loss maintenance may be due to the unidimensional approach to treatment. Obesity is often considered as merely an issue of energy imbalance. It may be better viewed as the endproduct of chronic adaptation in factors responsible for energy metabolism. Two critical factors are total energy expenditure in general, and the thermic effect of physical activity in particular.

Whilst excessive energy intake, metabolic aberrations, and genotype are all influential in the predisposition to body fat accumulation (James, 1995; Prentice \& Jebb, 1995; Saltsman \& Roberts, 1995), the increasing prevalence of overweight and obesity cannot be explained by dietary or genetic changes of the population, or by unpredictable decreases in resting metabolic rate (RMR; Shah \& Jeffery, 1991; Di Pietro, 1995; Prentice \& Jebb, 1995; Bouchard, 1996). Thus, the only way to be successful in weight management is (in addition to sensible dietary modification) to increase energy expenditure by voluntary physical activity (Bouchard, 1996).

A significant challenge is to advise and encourage the ideal exercise or physical activity as part of an individual's daily lifestyle across the lifespan. Key features of exercise prescription should be to optimize energy expenditure, to maintain the more-metabolically-active tissues, and to prevent musculo-skeletal injuries. The purpose of the present paper is to review the current knowledge of the science and the art of exercise prescription, with specific reference to weight management.

\section{The role of exercise in the aetiology of obesity}

Obesity is a multi-factorial condition, with the obesity phenotype determined by genetic, metabolic, and sociobehavioural factors. The relative contributions that excessive energy intake, inactivity, or metabolic aberrations have on energy balance remain debatable (Shah \& Jeffery, 1991; Stefanick, 1993; Di Pietro, 1995).

There is epidemiological evidence that an inverse relationship exists between physical activity and body weight, and that body fat is more favourably distributed in individuals who are physically active (Andersson et al. 1991; Wing et al. 1991; Di Pietro, 1995). Further, recent research into the relationship between body fatness and the different components of energy expenditure has shown that adiposity is inversely related to 'non-basal' energy expenditure (Schultz \& Schoeller, 1994). From such evidence it has been suggested that level of physical inactivity is a predisposing factor to obesity (Rising $e t$ al. 1994; Powers \& Howley, 1997). However, the associations between physical activity, energy expenditure and body composition are complex, and beyond the scope of the present review. Readers are referred to the following comprehensive epidemiological, clinical, and review papers on these aspects (Oscai, 1973; Epstein \& Wing, 1980; Ravussin et al. 1988; Tremblay et al. 1990; Ballor \& Keesey, 1991; Shah \& Jeffery, 1991; Stefanick, 1993; Williamson et al. 1993; Di Pietro, 1995; Foreyt et al. 1995).

\section{Rationale for the use of exercise in weight management}

Assessing exercise effectiveness by changes in total body weight can underestimate the effect on desirable body composition changes (Van Zant, 1992). Further, shorterterm studies are unable to assess exercise interventions that require a number of months to be effective. Studies of longer duration have shown that regular endurance exercise is effective in altering body composition of obese individuals even in the absence of dietary restriction (Bouchard et al. 1990; Frey-Hewitt et al. 1990; Lee et al. 1994). However, exercise is not necessary to achieve weight loss.

In accordance with the first law of thermodynamics, weight loss occurs as a function of an energy deficit, the size of which can be controlled (to a degree) by dietary restriction (Hill et al. 1993). Obesity management using dietary restriction is based on the assumption that obesity is a consequence of hyperphagia, or some metabolic aberration resulting in lower energy requirements. As both RMR and energy intake per unit body weight are comparable with those of normal-weight subjects (Wilmore \& Costill, 1994; Jebb \& Prentice, 1995) neither assumption holds in

\footnotetext{
Abbreviations: EPOC, excess post-exercise $\mathrm{O}_{2}$ consumption; FFM, fat-free mass; MET, metabolic equivalent; NEFA, non-esterified fatty acids; RMR, resting metabolic rate; SNS, sympathetic nervous system; $V_{\mathrm{O}_{2}}, \mathrm{O}_{2}$ uptake; $V_{\mathrm{O}_{2} \max }$, maximum $\mathrm{O}_{2}$ uptake.

*Corresponding author: Dr A. P. Hills, fax +6173864 3980, email a.hills@qut.edu.au
} 
most cases. Dietary restriction alone results in compensatory metabolic adaptations designed to preserve body mass (Ballor et al. 1990; de Groot et al. 1990; Saltzman \& Roberts, 1995). In contrast, exercise has been widely identified as being central to the long-term successful management of overweight and obesity (Pate, 1995; National Health \& Medical Research Council, 1997).

Exercise is a critical variable in optimizing body composition changes with weight loss, and in preventing weight regain (Hills \& Wahlqvist, 1994). More important, however, is the recent recognition of the role that exercise plays in the management of metabolic disorders often associated with excessive body fat levels. Consequently, the role that exercise plays in treating the overweight or obese condition can be categorized into two distinct but related areas: (1) exercise for body composition management, a subcomponent of physical fitness; (2) exercise for metabolic fitness (Bouchard, 1994).

\section{Metabolic $v$. physiological fitness}

Physical activity plays a pivotal role in gaining and maintaining physical fitness through improvements in functional capacity, muscular strength and endurance, flexibility, and body composition (Pollock et al. 1995). Further, recognizing the strong inverse relationship between regular aerobic exercise and degenerative disease development, physical activity is recommended as an effective primary and secondary prevention modality (Pollock \& Wilmore, 1990; American College of Sports Medicine, 1991; Fletcher et al. 1995). As body composition is a component of both physical fitness (physiological) and metabolic fitness, body weight will be influenced by exercise programmes designed for each purpose. The American College of Sports Medicine, along with other health-related agencies, has been instrumental in systematically recommending exercise prescriptions based on the most current scientific evidence.
A summary of recommendations outlined in Table 1 (adapted from Pollock et al. 1995) reflects the changing nature of research conducted to determine minimal and optimal levels of exercise needed to induce fitness-related adaptations in the cardiovascular-respiratory and musculoskeletal systems. Whilst the recommendations are generally accepted, Pollock et al. (1995) recognize that the guidelines lack precision and that more research is needed in the following areas: intensity prescription by heart rate for the elderly; resistance training; exercise adherence; training progression. One could add exercise prescription for weight management to this list.

Cross-sectional studies indicate that physically-active individuals have a reduced likelihood of developing hypertension and CHD (Paffenbarger et al. 1983; Sandvik et al. 1993). Exercise, with or without weight loss, significantly improves the plasma lipoprotein status by altering the content and composition of the major lipoprotein groups, and increasing HDL levels in particular (Despres, 1994). Reductions in visceral and total body fat have been demonstrated without alteration in maximum $\mathrm{O}_{2}$ uptake $\left(V_{\mathrm{O}_{2} \max }\right)$ in obese women who underwent a 14month endurance training programme. The reduced visceral adipose-tissue levels were accompanied by improved cardiovascular risk of reduced plasma cholesterol and LDL-cholesterol, and increased $\mathrm{HDL}_{2}-$ cholesterol (Schwartz et al. 1991; Despres \& Lamarche, 1994). Whilst the central adipocytes have a greater capacity to accumulate fatty acids rapidly, during periods of increased physical activity there is a more pronounced utilization of fatty acids from the visceral adipocytes and, thus, a reduced chance of developing the metabolic syndrome of non-insulin-dependent diabetes, hypertension and dyslipidaemia (Despres et al. 1991). Given that men display a preferential accumulation of body fat centrally, this is a possible reason for the suggestion that men respond better than women to the weight-loss effects of exercise (Ballor \& Keesey, 1991). Recent research on exercise prescription for metabolic disorders has identified both resistance-based and endur-

Table 1. Standards, guidelines, and position statements regarding physical activity for adults

\begin{tabular}{|c|c|c|c|c|c|}
\hline & Frequency & Intensity & Duration & Mode & Weight training \\
\hline $\begin{array}{l}\text { ACSM (1978) } \\
\text { position } \\
\text { statement }\end{array}$ & 3-5d/week & $\begin{array}{l}60-90 \% \mathrm{HR}_{\max } \text { or } 50- \\
85 \% V_{\mathrm{O}_{2} \max } \text { or } \\
\mathrm{HR}_{\max } \text { reserve }\end{array}$ & $15-60$ min continuous & $\begin{array}{l}\text { Traditional aero- } \\
\text { bic activities }\end{array}$ & Not stressed \\
\hline $\begin{array}{l}\text { ACSM (1990) } \\
\text { position stand }\end{array}$ & 3-5d/week & $\begin{array}{l}60-90 \% \mathrm{HR}_{\max } \text { or } 50- \\
85 \% V_{\mathrm{O}_{2} \max } \text { or } \\
\mathrm{HR}_{\max } \text { reserve }\end{array}$ & $20-60$ min continuous & Aerobic activities & $\begin{array}{l}\text { One set eight to twelve } \\
\text { reps; major muscle } \\
\text { groups; } 2 \mathrm{~d} / \text { week }\end{array}$ \\
\hline $\begin{array}{l}\text { ACSM (1995) } \\
\text { guidelines }\end{array}$ & 3-5d/week & $\begin{array}{l}50-90 \text { or } 60-90 \% \\
H R_{\max } \text { or } 40-85 \text { or } \\
50-85 \% V_{\mathrm{O}_{2} \max } \text { or } \\
\mathrm{HR}_{\max } \text { reserve }\end{array}$ & $20-60$ min continuous & $\begin{array}{l}\text { Aerobic activities } \\
\text { (expanded) }\end{array}$ & $\begin{array}{l}\text { One set eight to twelve } \\
\text { reps; major muscle } \\
\text { groups; } 2 \mathrm{~d} / \text { week }\end{array}$ \\
\hline $\begin{array}{l}1995 \text { AHA exercise } \\
\text { standards* }^{*}\end{array}$ & Minimum $3 d /$ week & $\begin{array}{c}50-60 \% V_{\mathrm{O}_{2} \max } \text { or } \\
\mathrm{HR}_{\max } \text { reserve }\end{array}$ & Minimum $30 \mathrm{~min}$ & $\begin{array}{l}\text { Heaith promotion } \\
\text { activities }\end{array}$ & $\begin{array}{l}\text { One set ten to fifteen } \\
\text { reps; eight to ten } \\
\text { exercises; 2- } \\
\text { 3d/week }\end{array}$ \\
\hline $\begin{array}{l}1995 \text { CDC and } \\
\text { ACSM public } \\
\text { health statement† }\end{array}$ & Daily & Moderate & Accumulate $30 \mathrm{~min} / \mathrm{d}$ & $\begin{array}{l}\text { Health promotion } \\
\text { activities }\end{array}$ & Addressed, not specific \\
\hline
\end{tabular}

ACSM, American College of Sports Medicine; AHA, American Heart Association; CDC, Centers for Disease Control and Prevention; $\mathrm{O}_{2}$ max, maximum $\mathrm{O}_{2}$ consumption; $\mathrm{HR}_{\max }$, maximum heart rate; rep, repetitions.

* See Fletcher et al. (1995).

+ See Pate et al. (1995). 
ance exercise training to be beneficial in improving blood lipid profiles, increasing left ventricular wall contractility, decreasing resting blood pressure, improving insulin sensitivity and glucose tolerance (Soukup \& Kovaleski, 1993; Dwyer et al. 1994; Katz \& Lowenthal, 1994).

Some controversy surrounds the relative associations between endurance training-induced changes in metabolic variables considered risk factors for conditions such as CHD and non-insulin-dependent diabetes mellitus, and the magnitude of improvements in cardio-respiratory fitness (Despres \& Lamarche, 1994). The American College of Sports Medicine (1990) position stand emphasized that the guidelines provided were based on scientific data relating the dose of endurance exercise to aerobic capacity and body composition outcomes. As outlined by Haskell (1994), there is an important distinction made between physical activity (and exercise in particular) as it relates to health $v$. fitness. The quantity and quality of exercise needed to obtain health-related benefits possibly differs from that recommended for fitness benefits. Prolonged endurance exercise of low intensity (approximately $50 \% V_{\mathrm{O}_{2} \max }$, performed on an almost daily basis appears to significantly improve metabolic variables through mechanisms that are likely to be independent of the training-related changes in cardio-respiratory fitness. Despres (1994) has suggested that for the purpose of treating and/or preventing metabolic disorders associated with excess adiposity, emphasis should not be placed on increasing $V_{\mathrm{O}_{2} \max }$ reflecting 'physiological fitness', but rather on 'metabolic fitness' via enhanced weight (or fat) loss, and related improvements in carbohydrate and lipid metabolism, through a substantial increase in daily energy expenditure. Whether it is more advantageous to lose weight through a negative energy balance or a negative fat balance, is somewhat debatable.

\section{Benefits of a negative energy balance $v$. a negative fat balance}

\section{Negative energy balance}

Second only to resting metabolism, the thermic effect of physical activity has the greatest potential to influence the amount of energy expended by an individual. Consequently, it is also the most variable component of energy expenditure, ranging between 5 and $30 \%$ of individual daily energy expenditure (Poehlman, 1989; Calles-Escandon \& Horton, 1992). Whilst the amount of energy required to achieve any given task is greater for a person of greater mass, the inter-individual variance in the total daily thermic effect of exercise is primarily a function of the volume of intentional physical activity undertaken. The amount of energy expended during exercise is related both to the characteristics of the activity (intensity, mode and duration) and the body size and fitness status of the individual (Hill et al. 1995).

Exercise provides the additional energetic benefits of elevated energy expenditure in the post-exercise period as shown by 'excess post-exercise $\mathrm{O}_{2}$ consumption' (EPOC; Bahr \& Maehlum, 1986; Goldberg et al. 1990), and a possible reversal of the diet-induced suppression of basal metabolism (Tremblay et al. 1990). The quantitative significance of EPOC for weight loss has been questioned, as it may average only $38-125 \mathrm{~kJ}$ for low to moderate exercise of durations less than $80 \mathrm{~min}$ (Poehlman et al. 1991). However, the reversal of dietary-induced metabolic suppression by exercise is well founded (Thompson et al. 1996). Potential reasons for the dietary-induced reduction include decreases in triiodothyronine concentration, sympathetic nervous system (SNS) activity as indicated by noradrenaline kinetics, and fat-free mass (FFM; Ravussin \& Tataranni, 1996; Saris, 1996). A meta-analysis of the effects of diet and diet-plus-exercise interventions on RMR concluded that moderate-intensity exercise $(51-70 \%$ $V_{\mathrm{O}_{2} \text { max }}$ ) performed $31-60 \mathrm{~min} / \mathrm{d}, 4-5 \mathrm{~d}$ per week, is sufficient to reverse some of the decreases in RMR resulting from dietary restriction (Thompson et al. 1996). Further, there is evidence that in obese individuals the adaptive responsiveness of the SNS to changing energy status is blunted (Ravussin \& Tataranni, 1996; Saris, 1996). Hence, as the altered substrate demands during exercise require increased activation of SNS, which in turn results in increases in RMR and lipid oxidation, exercise may play an important role in overcoming the impaired lipid oxidation in muscle of obese individuals (Saris, 1996).

\section{Negative fat balance}

As a consequence of endurance exercise training, there are a number of biochemical adaptations which favour maintenance of homeostasis and improve the muscle's capacity to produce energy aerobically (Powers \& Howley, 1997). Such adaptations include increased mitochondrial number, increased capillary density, and changes in mitochondrial oxidative enzymes (Holloszy \& Coyle, 1983; Wibom et al. 1992). These biochemical changes result in an increased utilization of fat (fatty acid oxidation) in preference to carbohydrate during submaximal exercise (Henriksson, 1977) via the following mechanisms: an increased adrenaline-stimulated hydrolysis from subcutaneous adipose tissue (Crampes et al. 1989; Riviere et al. 1989); an increase in the capacity of the trained muscle to oxidize lipids (Bjorntorp, 1990); increased hydrolysis of triacylglycerols within the trained muscle (Hurley et al. 1986); increased hydrolysis of circulating triacylglycerols through lipoprotein lipase (EC 3.1.1.34) activity (Haskell, 1984); increased insulin concentrations, a primary inhibiting factor to lipid mobilization (Bjorntorp, 1990).

With the onset of dynamic large muscle mass exercise, the increase in skeletal muscle uptake of non-esterified fatty acids (NEFA) exceeds the slower-to-increase rate of lipolysis, resulting in a decreased plasma NEFA concentration during the initial 10-15 min of work (Friedberg et al. 1960; Havel et al. 1967). The work of Wolfe et al. (1990) indicated that the subsequent increased rate of lipolysis results in the proportion of energy that is derived from NEFA gradually increasing with longer duration of the exercise at a fixed submaximal work rate. After $15-20 \mathrm{~min}$ of exercise at $40 \% V_{\mathrm{O}_{2} \max }$, plasma NEFA turnover is three to four times the resting rate, and increases progressively to approximately six times resting rate after $4 \mathrm{~h}$ at this intensity (Zierler, 1976). For exercise at intensities below $40 \% V_{\mathrm{O}_{2} \text { max }}$, the turnover rate of plasma NEFA is such that 
the substrate requirements of skeletal muscle can be met entirely from this source (Martin, 1996). These findings indicate that exercise bouts of long duration may be more beneficial in terms of fatty acid consumption than the same amount of exercise accumulated through several bouts of short duration.

Low-intensity activities are professed by some to be advantageous for their 'fat burning' capacity. However, research on endurance-trained athletes shows that whilst at low intensities (e.g. $25 \% V_{\mathrm{O}_{2} \text { max }}$ ) plasma-borne NEFA do provide nearly all the substrate required for exercise, NEFA provide $40-60 \%$ of the total fuel required for exercise at $65 \% V_{\mathrm{O}_{2} \max }$ (Romijn et al. 1993). In absolute terms, for the energy required to exercise at $65 \% V_{\mathrm{O}_{\text {max }}}$, the rate of fat oxidation is approximately $40 \%$ higher than at $25 \%$ $V_{\mathrm{O}_{2} \max }$. Hence, while more energy is being expended, the absolute amount of NEFA being used is equivalent. Tremblay et al. (1994) demonstrated that a training programme incorporating intermittent high-intensity exercise (approximately $85 \% \quad V_{\mathrm{O}_{2} \text { max }}$ ) resulted in a greater reduction in skinfold thicknesses than a similar duration of exercise at a lower target heart rate range. These findings are supported by a meta-analysis of the factors affecting changes in body weight and body composition. Ballor \& Keesey (1991) concluded that the total energy expended in exercise is directly related, in a dose-response relationship, to the effectiveness of exercise.

\section{The science of exercise prescription for weight management}

\section{American College of Sports Medicine guidelines}

Weight-loss guidelines promoted by the American College of Sports Medicine (1995) support a combined mild energy restriction with regular endurance exercise. A desirable weight-loss programme should balance exercise intensity and duration to promote a high total energy expenditure, approximately $1250-2090 \mathrm{~kJ}$ per session and $4180-8360 \mathrm{~kJ}$ per week for adults. Given that obese individuals are at an increased risk for musculo-skeletal injury, it is recommended that the intensity of exercise be maintained at or below the intensity identified for improvement of cardiorespiratory endurance. Additionally, non-weight-bearing activities and/or rotation of exercise modalities, as well as frequent modification to the exercise frequency and duration, may also be required (American College of Sports Medicine, 1995).

Thus, the current guidelines for exercise prescription for weight management are somewhat general in nature, and consequently there is much room for interpretation. Given the relative paucity of scientifically-controlled research on exercise prescription for weight management, many studies suggest the need for further research to identify more specifically the amount, type, and intensity of exercise required to produce weight loss or maintain ideal body weight, while maximizing other desirable physiological and metabolic adaptations (Stefanick, 1993; Haskell, 1994; Zelasko, 1995; Thompson et al. 1996).

\section{Dose-response}

The exercise dose is characterized by the intensity, frequency, duration, and type or modality of exercise: modality (resistance weight training, cardiovascular endurance training); frequency (number of $d$ per week, number of sessions per $\mathrm{d}$ ); duration (period (min) of exercise, total energy expended $(\mathrm{kJ})$, total energy $(\mathrm{kJ}) / \mathrm{kg}$ body weight); intensity $\left(\% V_{\mathrm{O}_{2} \text { max }}, \%\right.$ maximum heart rate, $\%$ heart rate reserve, rating of perceived exertion, lactate threshold, metabolic equivalent (MET)).

\section{Exercise modalities for weight loss}

All exercise modalities, if undertaken regularly at an appropriate energy expending threshold, will result in significant reductions in body mass and body fatness (McArdle et al. 1996). From an energy expenditure perspective, there is no selective effect of training mode on body composition changes if total work output is equivalent (Pollock et al. 1977). However, there are differences in the suitability of exercises for the overweight, and the obese in particular. Optimal exercise modalities minimize the cardiac effort whilst maximizing conditioning (DeVries \& Housh, 1994).

Walking. Walking is the most effective modality for any individual initiating an exercise programme (Porcari et al. 1989a; Buskirk, 1993). The advantages of walking over other modalities include: avoidance of musculo-skeletal problems associated with running; the traffic hazards associated with cycling; inconvenience of finding a swimming pool; requiring no skill acquisition; suitable for most places and times; the ability to produce a training effect (Buskirk, 1993). Compared with running, the ground reaction forces are 3.6 times less for walking (Voloshin, 1988), resulting in less risk of injury.

When body weight is accounted for, the most important determinant of the energetic cost of walking is walking speed (Blessey et al. 1976). While the relationship between energy cost and walking speed is linear for speeds between 4 and $6 \mathrm{~km} / \mathrm{h}$, and curvilinear between 6 and $8 \mathrm{~km} / \mathrm{h}$, at any given speed the relationship between energy cost and grade is linear (Ebbeling et al. 1988). These relationships allow for the prediction of energy expenditure using regression equations (Porcari et al. 1989a). In order to achieve an aerobic training threshold of $70 \%$ maximum heart rate, Porcari et al. (1987) recommend that depending on initial level of fitness, women and men need to walk between 5.6 and $6.4 \mathrm{~km} / \mathrm{h}$, and 6.4 and $7.2 \mathrm{~km} / \mathrm{h}$ respectively. Jette (1975) developed the following equation ( $r$ 0.86) to estimate the walking speed ( $\mathrm{min} / \mathrm{mile}$ ) that would achieve a target energy expenditure: speed $=44.7-(0.45 \times$ target $)$ $-(12.3 \times$ height $)+(0.015 \times$ weight $)$ where target is the target energy expenditure ( $\mathrm{ml} / \mathrm{kg}$ per $\mathrm{min})$ and height and weight are expressed in $\mathrm{m}$ and $\mathrm{kg}$ respectively. To assist in cardiac rehabilitation, Cornish (1983) outlined a walking programme that enables exercise to be prescribed to an accuracy of $1 \mathrm{~m} / \mathrm{min}$ or two pulse beats $/ \mathrm{min}$. The basic principle involves individuals walking or jogging around a marked circular course, completing one circuit per min. 
The radius of the circle increases marginally as the individual's fitness improves, and a timing device is employed to ensure a uniform pace is maintained by each participant.

Research has demonstrated that the energy cost and intensity of walking can be increased by adding weight to the head, hands, wrists, ankles or torso (Keren et al. 1981; Graves et al. 1987, 1988; Porcari et al. 1989a). Predominantly, loads of $0.45-2.2 \mathrm{~kg}$ have been employed (Graves et al. 1988), but much heavier weights have been utilized when carried on the torso (Robertson et al. 1982; Walcott et al. 1986). Whilst hand weights held by the side without arm movement do not increase $V_{\mathrm{O}_{2} \max }$ significantly (Francis \& Hoobler, 1986), a pumping action of the arms does (Makalous et al. 1988). Graves et al. (1988) noted a twelve beats per min increase in heart rate and a 1 MET increase in energy cost when $1.36 \mathrm{~kg}$ hand weights were employed. Although ankle weights elicit a lower increase in energy expenditure than hand weights for the same load (Graves et al. 1988), they have produced beneficial training effects for individuals with low levels of cardio-respiratory fitness (Pandolf \& Goldman, 1975; Burse et al. 1979). External loads carried on the torso must be 'substantial' to increase energy expenditure significantly (Porcari et al. $1989 b$ ). Energy expenditure increases were noted when loads representing $15 \%$ but not $7.5 \%$ of total body mass were worn at the waist (Robertson et al. 1982). However, Walcott et al. (1986) noted that compared with the unweighted condition, carrying a weight vest containing $40 \%$ of body mass at $5.6 \mathrm{~km} / \mathrm{h}$ increased energy expenditure by only $7.5 \mathrm{~kJ} / \mathrm{min}$ for women and $9.2 \mathrm{~kJ} / \mathrm{min}$ for men. Despite the potential to increase energy expenditure when walking, carrying weights may be contra-indicated for individuals with high blood pressure or an exaggerated blood pressure response to exercise, and for individuals with orthopaedic problems.

Aqua. Due to the buoyancy effect, exercise performed in water has the benefit of reduced loading on joints and, thus, permits the obese individual to progress more rapidly in terms of volume of exercise (frequency, duration, intensity) with less risk of injury (Sheldahl, 1985). Further, the greater specific heat and thermoconductivity of water compared with air increases the capacity to remove body heat in cool water (Bullard \& Rapp, 1970). Thus, exercise in cool water can reduce thermoregulation problems exaggerated for the obese in the heat, and increase the comfort of movement (Bar-Or et al. 1969; Vroman et al. 1983). In contrast, exercising in cold water is tolerated better by individuals who display a greater insulating layer of subcutaneous adipose tissue (Sheldahl et al. 1982). Research to assess the efficacy of exercising individuals on a cycle ergometer immersed to their shoulders in water revealed that higher work intensities could be tolerated by the obese individuals, particularly in cold $\left(20^{\circ}\right)$ water (O'Hara et al. 1977, 1979; Sheldahl et al. 1982; Avellini et al. 1983).

Provided the individual is adequately skilled, swimming also has the advantages of reduced weight-bearing stress, reduced heat stress in cold water, and the ability to exercise at an aerobic threshold (Sheldahl, 1985). Other water-based activities include kicking with a board or holding the side of the pool, aqua-aerobics (pool-based exercises to music), walking or running in either deep or shallow water, and strength exercises using water resistance. It must be recognized that upright exercises in the water exert a hydrostatic pressure gradient on the body surface, which increases the venous return from the lower extremities (Arborelius et al. 1972; Begin et al. 1976). Consequently, there is an increase in central blood volume and venous pressure, and increases in cardiac output and stroke volume of $25 \%$ or more.

The effectiveness of deep-water running on maintenance of aerobic performance has been demonstrated by a number of studies. No significant differences in body composition, cardio-respiratory performance, or blood metabolites (glucose, lactate, noradrenaline) were noted between 6 weeks of land and water-based running in trained athletes (Wilber et al. 1996). While $V_{\mathrm{O}_{2} \max }$ was the most important predictor of perceived exertion during deep-water running (Brown et al. $1996 a$ ), ratings of perceived exertion were significantly higher in deep-water running than treadmill running at the same cadence (Brown et al. 1996b). Svedenhag \& Seger (1992) noted that for a given $V_{\mathrm{O}_{2}}$, heart rate was eight to eleven beats per min lower than treadmill running irrespective of exercise intensity. Further, during deepwater running both the $V_{\mathrm{O}_{2} \max }$ and heart rate were lower, while perceived exertion, respiratory exchange ratio, and blood lactate were higher at submaximal efforts (Ritchie \& Hopkins, 1991). The authors suggested that the exercise effects of deep-water running were more comparable with cycle ergometry responses, and that both the external load and an altered running technique add to an increased anaerobic metabolism during supported deep-water running. Butts et al. (1991) also noted the magnitude of physiological responses for deep-water running were comparable with cycle ergometry, thus not precluding deep-water running as a training technique. Such findings suggest that training intensities for water running would be better derived from cycle ergometry tests, or if from treadmill tests, a correction factor needs to be employed. These studies hold promise for the use of deep-water running in prescribing exercise for the obese.

Resistance weight training. There is overwhelming support for the use of resistance weight training in exercise prescription for people of all ages, and considerable scope for the overweight and obese (American College of Sports Medicine, 1990; Pollock et al. 1994; Feigenbaum \& Pollock, 1997). Given the recognition that long-term weight management is dependent on the maintenance of metabolically-active tissue, resistance weight training is an obvious choice for inclusion in an exercise programme. Adding strength training to a programme of regular physical activity will help decrease the risk of "chronic diseases' while improving quality of life and functionality, thereby allowing people of all ages to improve and maintain their health and independent lifestyle (Pollock \& Vincent, 1996). The American College of Sports Medicine (1990, 1995), American Heart Association (Fletcher et al. 1995), and the Surgeon General's Report, Physical Activity and Health (US Department of Health and Human Services, 1996) have recommended resistance weight training, with gains achieved through performing one set 
of eight to twelve repetitions (persons under 50 years) or ten to fifteen repetitions (persons over 50 years) of eight to twelve exercises two to three times per week. In addition to gains or maintenance of FFM during weight loss, the average energy expenditure of circuit resistance weight training is approximately $38 \mathrm{~kJ} / \mathrm{min}$, and can produce a substantial energy output during a 30-60 min workout (Ballor et al. 1989).

\section{Exercise frequency for weight loss}

Pollock et al. (1975) researched the training frequency required to significantly change the body composition of individuals who walked or ran for between 30 and $47 \mathrm{~min} / \mathrm{d}$ at $80-95 \%$ maximum heart rate for 20 weeks. Whilst training twice weekly was not instrumental in changing body weight, skinfolds, or percentage body fat, exercising 3 and $4 \mathrm{~d}$ weekly was effective. Further, the $4 \mathrm{~d}$ weekly group lost significantly more weight and fat than the $3 \mathrm{~d}$ weekly group. Thus, while exercising $3 \mathrm{~d}$ weekly will produce changes, training more frequently will be more effective. For general health benefits, it has been recommended in the Surgeon General's Report (US Department of Health and Human Services, 1996) that all people should aim to accumulate $30 \mathrm{~min}$ of moderate-intensity physical activity on most, and preferably all, days of the week.

\section{Exercise duration for weight loss}

A study by Milesis et al. (1976) investigated the influence of exercise duration on weight loss in a group of previously sedentary men. The subjects were divided into four groups, a control group who did not exercise, and three exercise groups: 15,30 , or $45 \mathrm{~min}$ per session. Whilst the three exercise groups decreased in body fat and waist girth significantly more than the control group, $45 \mathrm{~min}$ elicited significantly greater changes than 15 or $30 \mathrm{~min}$ of exercise. Despres (1994) has suggested that walking for at least $1 \mathrm{~h}$ on most days represents the best exercise prescription for most obese individuals. However, the most definitive suggestion to date, is that the duration of exercise should be long enough to have reached a threshold of $1250 \mathrm{~kJ}$ (Pollock \& Jackson, 1977).

\section{Exercise intensity for weight loss}

For weight loss, maximizing energy expenditure may be superior to a regimen designed to maximize the use of fat during the exercise bout. Of the 1366 women and 1257 men recruited for the 1981 Canada Fitness Survey, Tremblay et al. (1994) found that individuals practising vigorous activities on a regular basis had lower subcutaneous skinfold thicknesses and waist: hip ratios than those not involved in such activities. These differences were reported to remain statistically significant after covariance analyses to remove the effect of estimated total energy expenditure of leisure-time activities, and appear to indicate that exercise undertaken at a higher intensity is more advantageous in preventing body fat gain. In contrast, more recent intervention-based research has shown no effect of exercise intensity on body composition changes, either with or without dietary restriction, when total energy expended weekly is comparable (Grediagin et al. 1995; Leutholtz et al. 1995).

Leutholtz et al. (1995) found that while on a supplemented $1760 \mathrm{~kJ} / \mathrm{d}$ fast, exercise at 40 and $60 \%$ of the heart rate reserve affected body composition of obese men and women to a similar extent when total training volume was held constant at $3760 \mathrm{~kJ} /$ week. The study involved 12 weeks of training, three sessions weekly, with subjects randomized into groups that exercised at target heart rates corresponding to 40 and $60 \%$ of the heart rate reserve at the beginning of the programme. In both groups, decreases in body weight (15.3 (SD 6.7) kg) and body fat (14.9 (SD $5.0) \mathrm{kg}$ ) were significant, while lean mass remained unchanged. Grediagin et al. (1995) randomly assigned untrained, moderately-overfat, weight-stable women to either high-intensity $\left(80 \% V_{\mathrm{O}_{2} \max }\right)$ or low-intensity $(50 \%$ $\left.V_{\mathrm{O}_{2} \max }\right)$ exercise groups for four sessions weekly for 12 weeks, with each session of a duration sufficient to expend $1250 \mathrm{~kJ}$. During the study, the subjects were instructed to maintain their normal diet and activity patterns. While there were no significant differences between groups for change in weight, percentage body fat, fat mass, FFM, sum of skinfold measurements, or sum of circumferences, the high-intensity group tended to have a greater increase in FFM. Grediagin et al. (1995) concluded that fat loss is a function of energy expended rather than exercise intensity. Thus, if fat loss is the goal and time is limited, persons should exercise at as high an intensity as tolerable to expend as much energy as possible during the time available. However, as previously alluded to, in addition to the substrate and energy utilization consideration, there are other issues including cardiovascular and musculoskeletal risk, metabolic $v$. cardiovascular fitness, and adherence issues to consider when prescribing the exercise intensity.

\section{The art of exercise prescription for weight management}

\section{Intensity prescription}

Arguably the most difficult aspect of exercise prescription lies in defining the exercise intensity for an individual, and in monitoring this intensity once an appropriate level has been prescribed (Pollock et al. 1995). Although the relative intensity of exercise can be addressed through prescription based on a percentage of the maximal values, these values may not be the most appropriate measure of endurance capacity, as they are not measures of a level of intensity able to be maintained for prolonged periods of time. It may be more appropriate to measure a submaximal marker of intensity that is related to a level of exercise intensity at which adaptations may occur, and which is able to reflect any changes in exercise capacity. As outlined in Table 2, research has delineated the association between these variables.

Implementing these variables requires either direct measurement of the maximal values, a prediction of the maximal values from a submaximal test, or the estimation from a predictive equation. Whilst the direct measurement 
Table 2. Classification of exercise intensity based on 30-60 min of endurance training (Adapted from Pollock \& Wilmore, 1990)

\begin{tabular}{|c|c|c|c|}
\hline \multicolumn{2}{|c|}{ Relative intensity (\%) } & \multirow[b]{2}{*}{ Rating of perceived exertion* } & \multirow[b]{2}{*}{ Classification of intensity } \\
\hline$H R_{\max }$ & $V_{\mathrm{O}_{2} \max }$ or $\mathrm{HR}_{\max }$ reserve & & \\
\hline$<35$ & $<30$ & $<10$ & Very light \\
\hline $35-59$ & $30-49$ & $10-11$ & Light \\
\hline $60-79$ & $50-74$ & $12-13$ & Moderate (somewhat hard) \\
\hline $80-89$ & $75-84$ & $14-16$ & Heavy \\
\hline$\geq 90$ & $\geq 85$ & $>16$ & Very heavy \\
\hline
\end{tabular}

of maximal values is the most accurate method of assessment, it may be considered inappropriate for 'at risk' populations, and can result in reinforcement of the negative association with exercise, reducing the likelihood of adherence to subsequent prescription. Further, tests conducted on sedentary individuals more commonly reflect measurement of peak, rather than maximal values (Brooks et al. 1996). Additionally, the expense of the equipment required and the time needed for maximal testing can make it impractical for use in many exercise settings (Porcari et al. 1989a). In contrast, extrapolations of training thresholds from submaximal tests, or predictions from generalized equations are associated with greater error.

Heart rate. Heart-rate monitoring is a convenient method to assess exercise intensity. One shortcoming in this area, but not in the accuracy of monitoring, is in the methods used to determine an appropriate training level. Heart rate is closely associated with exercise intensity, with the relationship between heart rate and $V_{\mathrm{O}_{2}}$ being linear with increasing intensity. There are a number of approaches for calculating an appropriate target heart rate range. The best approach involves a plot of the relationship between exercise heart rate and aerobic capacity $\left(V_{\mathrm{O}_{2}}\right)$ or lactate concentration at given work levels during a maximal exercise test, from which the range of heart rates associated with given percentages of functional capacity can be determined. More commonly, predictive approaches, which use the percentage of heart rate reserve (difference between the maximum and resting heart rates), or a fixed percentage of the maximum heart rate, are employed. However, the variation in the most-commonly-utilized prediction equation for maximum heart rate $(220-$ age $)$, has been calculated as \pm ten beats per min in normal subjects (American College of Sports Medicine, 1995). Research by Miller et al. (1993) suggests that for obese individuals the equation $200-(0.5$ age $)$ is more accurate.

Lactate threshold. Although beyond the scope of the present paper, the use of blood lactate concentration to assess relative intensity of exercise effort is well supported (Belman \& Gaesser, 1990; Aellen et al. 1993; Casaburi et al. 1995), and readers are referred to an excellent review by Weltman (1995). In short, the lactate threshold is highly correlated with endurance performance, independent of $V_{\mathrm{O}_{2} \max }$ and gender (Tanaka et al. 1990; Evans et al. 1995). Further, the lactate threshold, as well as representing a level at which training adaptations are most significant, is itself a trainable physiological variable in both untrained and highly-trained individuals (Belman \& Gaesser, 1990; Casaburi et al. 1995; Weltman, 1995). The lactate threshold, therefore, is able to provide a submaximal marker of exercise intensity that is relative to the training status of the individual. It is possible that the lactate threshold may also represent a level of maximum energy expenditure at a tolerable workload. One disadvantage of the lactate threshold for the prescription of exercise intensity is the invasive nature of its direct measurement. As yet, there are no means by which the lactate threshold can be indirectly measured or estimated accurately. Our recent work suggests that there may be merit in the use of predictive equations to define training thresholds based on heart rate and age and the relationship with blood lactate at given workloads (Hills \& Byrne, unpublished results).

Perceived exertion. Perceived exertion is a psychophysical measure of an individual's perception of a level of exercise or work intensity. This measure may be expressed using a variety of scales such as the Borg 6-20, and the Borg 0-10 (category-ratio) scales (Noble et al. 1983; Borg, 1985). As it has been proposed that both perceived exertion and heart rate increase with the intensity of exercise either one may be predicted from the measurement of the other, as well as being used as an estimate of exercise intensity. However, perceived exertion, being composed of a multitude of psychological and physiological factors, therefore, may be a more accurate indicator of intensity than any one of these factors (Williams \& Eston, 1989). Psychological variables which may affect perceived rate of exertion include personality traits, previous exercise experience and distraction, each of which can lead to a decrease in reported values of perceived exertion (Williams \& Eston, 1989).

Physiological variables such as blood lactate accumulation, carbohydrate depletion, respiration rate, hydration state and aerobic capacity as well as heart rate can also influence perceived exertion (Barr et al. 1991; Burgess et al. 1991; Hetzler et al. 1991; Seip et al. 1991). Blood lactate, in particular, is closely related to perceived exertion at specific workloads, regardless of training state or training modality (Hetzler et al. 1991; Seip et al. 1991). The lactate threshold corresponds to perceived exertion values of 11.0 (SD 2.0), and fixed blood lactate concentrations of $2 \cdot 0,2 \cdot 5$, and $4.0 \mathrm{mmol} / 1$ correspond with ratings of 13.7 (SD 2.1), 14.5 (SD 1.8) and 16.5 (SD 2.3) respectively for males (Glass et al. 1991; Seip et al. 1991).

It may be concluded from recent work assessing the efficacy of perceived exertion ratings of athletic, sedentary, 
overweight, or cardiac rehabilitation patients, that scales of ratings of perceived exertion do have a valid role to play in the monitoring of exercise intensity. However, there are many factors to be taken into consideration, including the need for appropriate education, before scales of ratings of perceived exertion can be used effectively (Glass et al. 1991; Dishman, 1994; Dunbar et al. 1994, 1996a,b; Jakicic et al. 1995; Dunbar \& Bursztyn, 1996; Eston \& Connolly, 1996).

\section{Summary}

The debate surrounding the level of intensity of exercise that is best for health improvement has potentially clouded the issue of optimal exercise prescription for weight management. Low-intensity activity is potentially superior to moderate to high intensity for improving metabolic risk factors, and accumulated small bouts of physical activity are as effective to this end as single longer bouts, as long as the overall volume of energy expenditure is equivalent. What should not be forgotten however, is that for weightloss, it is the total volume of energy expended that will dictate the size of the energy deficit imposed, not the composition of the exercise per se.

Exercise prescription for weight management is a conundrum. Whilst it is the total volume of energy expended that will dictate the magnitude of weight lost, not the composition of the exercise per se, it is the nature of the exercise prescription that will dictate the long-term success of an exercise programme. It is how well the exercise prescription is individualized that influences tolerance of and interest in the programme and, thus, the adherence to it in the long term.

\section{References}

Aellen R, Hollmann W \& Boutellier U (1993) Effects of aerobic and anaerobic training on plasma lipoproteins. International Journal of Sports Medicine 14, 396-400.

American College of Sports Medicine (1990) Position stand on the recommended quantity and quality of exercise for developing and maintaining cardiorespiratory and muscular fitness in healthy adults. Medicine and Science in Sports and Exercise 22, 265-274.

American College of Sports Medicine (1991) Guidelines for Exercise Testing and Prescription, 4th ed. Philadelphia, PA: Lea \& Febiger.

American College of Sports Medicine (1995) Guidelines for Exercise Testing and Prescription, 5th ed. Philadelphia, PA: Lea \& Febiger.

Andersson B, Xu X, Rebuffe-Scrive M, Terning K, Krotkiewski M \& Bjorntorp P (1991) The effects of exercise training on body composition and metabolism in men and women. International Journal of Obesity 15, 75-81.

Arborelius M, Balldin UI \& Lundgren CEG (1972) Hemodynamic changes in man during immersion with the head above water. Aerospace Medicine 43, 592-598.

Avellini BA, Shapiro Y \& Pandolf KV (1983) Cardiorespiratory physical training in water and on land. European Journal of Applied Physiology 50, 255-264.

Bahr R \& Maehlum S (1986) Excess post-exercise oxygen consumption. A short review. Acta Physiologica Scandinavica 128, Suppl. 556, 99-104.
Ballor DL, Becque MD, Marks CR, Nau KL \& Katch VL (1989) Physiological responses to nine different exercise:rest protocols. Medicine and Science in Sports and Exercise 21, 90-95.

Ballor DL \& Keesey RE (1991) A meta-analysis of the factors affecting exercise-induced changes in body mass, fat mass and fat-free mass in males and females. Internationai Joumal of Obesity 15, 717-726.

Ballor D, McCarthy J \& Wilterdink E (1990) Exercise intensity does not affect the composition of diet- and exercise-induced body mass loss. American Journal of Clinical Nutrition 51, $142-146$.

Bar-Or O, Lundegren HM \& Buskirk ER (1969) Heat tolerance of exercising obese and lean women. Joumal of Applied Physiology 26, 403-409.

Barr S, Costill D \& Fink W (1991) Fluid replacement during prolonged exercise: effects of water, saline, or no fluid. Medicine and Science in Sports and Exercise 23, 811-817.

Begin R, Epstein M, Sackner MA, Levinson R, Dougherty R \& Duncan D (1976) Effect of water immersion to the neck on pulmonary circulation and tissue volume in man. Journal of Applied Physiology 40, 293-299.

Belman M \& Gaesser G (1990) Exercise training below and above the lactate threshold in the elderly. Medicine and Science in Sports and Exercise 23, 562-568.

Bjorntorp P (1990) Adipose tissue adaptation to exercise. In Exercise, Fitness and Health: A Consensus of Current Knowledge, pp. 315-323 [C Bouchard, RJ Shephard, T Stephens, JR Sutton and BD McPherson, editors]. Champaign, IL: Human Kinetics.

Blessey RL, Hislop HJ, Waters RL \& Antonelli D (1976) Metabolic energy cost of unrestrained walking. Physical Therapy 56, 1019-1024.

Borg G (1985) An Introduction to Borg's RPE-Scale. Ithaca, NY: Mouvement Publications.

Bouchard C (1994) Genetic variation in exercise and obesity. In Exercise and Obesity, pp. 33-48 [AP Hills and ML Wahlquist, editors]. London: Smith-Gordon.

Bouchard C (1996) Dietary management: what works and what doesn't (Panel discussion). Proceedings of a Symposium by the National Heart Foundation of Australia: Wrestling with Obesity, pp. 39-47.

Bouchard C, Tremblay A, Nadeau A, Dussault J, Després JP, Theriault G, Lupien PJ, Serresse O, Boulay MR \& Fournier G (1990) Long-term exercise training with constant energy intake. 1: Effect on body composition and selected metabolic variables. International Journal of Obesity 14, 57-73.

Brooks GA, Fahey TD \& White TP (1996) Exercise Physiology, Human Bioenergetics and its Applications, 2nd ed. Mountain View, CA: Mayfield Publishing Company.

Brown SP, Chitwood LF, Beason KR \& McLemore DR (1996a) Perceptual responses to deep water running and treadmill exercise. Perceptual and Motor Skills 83, 131-139.

Brown SP, Chitwood LF, Beason KR \& McLemore DR (1996b). Physiological correlates with perceived exertion during deep water running. Perceptual and Motor Skills 83, 155-162.

Bullard RW \& Rapp GM (1970) Problems of body heat loss in water immersion. Aerospace Medicine 41, 1269-1277.

Burgess ML, Robertson RJ, Davis JM \& Norris JM (1991) RPE, blood glucose and carbohydrate oxidation during exercise: effects of glucose feeding. Medicine and Science in Sports and Exercise 23, 353-359.

Burse RL, Pandolf KB \& Goldman RF (1979) Physical conditioning of sedentary young man with ankle weights during working hours. Ergonomics 22, 69-78.

Buskirk ER (1993) Obesity. In Exercise Testing and Exercise Prescription for Special Cases. Theoretical Basis and Clinical 
Application, pp. 185-210 [JS Skinner, editor]. Philadelphia, PA: Lea \& Febiger.

Butts NK, Tucker M \& Greening C (1991) Physiologic responses to maximal treadmill and deep water running in men and women. American Journal of Sports Medicine 19, 612-614.

Calles-Escandon J \& Horton ES (1992) The thermogenic role of exercise in the treatment of morbid obesity: a critical evaluation. American Journal of Clinical Nutrition 55, S533S537.

Casaburi RT, Storer TW, Sullivan SS \& Wasserman K (1995) Evaluation of blood lactate as an intensity criterion for exercise training. Medicine and Science in Sports and Exercise 27, 852862.

Cornish G (1983) Personal exercise prescription. Cardiac rehabilitation and preventive medicine. Medical Journal of Australia 4, 163-165.

Crampes F, Riviere D, Beauvill M, Marceron M \& Garrigues M (1989) Lipolytic response of adipocytes to epinephrine in sedentary and exercise-trained subjects: sex-related differences. European Journal of Applied Physiology 59, 249-255.

de Groot, L, van Es A, van Raaij J, Vogt J \& Hautvast J (1990) Energy metabolism of overweight women 1 mo and $1 \mathrm{y}$ after an 8-week slimming period. American Journal of Clinical Nutrition 51, 578-583.

Despres JP (1994) Metabolic dysfunction and exercise. In Exercise and Obesity, pp. 71-84 [AP Hills and ML Wahlquist, editors]. London: Smith-Gordon.

Despres JP \& Lamarche B (1994) Low-intensity endurance exercise training, plasma lipoproteins and the risk of coronary heart disease. Joumal of International Medicine 236, 7-22.

Despres JP, Pouliot MC, Moorjani S, Nadeau A, Tremblay A, Lupien PJ, Theriault G \& Bouchard C (1991) Loss of abdominal fat and metabolic response to exercise training in obese women. American Journal of Physiology 261, E159-E167.

DeVries HA \& Housh TJ (1994) Physiology of Exercise, 5th ed. Madison, WI: Brown \& Benchmark.

DePietro L (1995) Physical activity, body weight, and adiposity: an epidemiological perspective. Exercise and Sport Sciences Reviews 23, 275-303.

Dishman RK (1994) Prescribing exercise intensity for healthy adults using perceived exertion. Medicine and Science in Sports and Exercise 26, 1087-1094.

Dunbar CC \& Bursztyn DA (1996) The slope method of prescribing exercise with ratings of perceived exertion (RPE). Perceptual and Motor Skills 83, 91-97.

Dunbar CC, Glickman-Weiss EL, Edwards WW, Conley P \& Quiroz A (1996a) Three-point method of prescribing exercise with ratings of perceived exertion is valid for cardiac patients. Perceptual and Motor Skills 83, 384-386.

Dunbar CC, Goris C, Michielli DW \& Kalinski MI (1994) Accuracy and reproducibility of an exercise prescription based on Ratings of Perceived Exertion for treadmill and cycle ergometer exercise. Perceptual and Motor Skills 78, 13351344.

Dunbar CC, Kalinski MI \& Robertson RJ (1996b) A new method for preseribing exercise: three-point ratings of perceived exertion. Perceptual and Motor Skills 82, 139-146.

Dwyer GB, Wallace IP \& Whaley MH (1994) Influence of metabolic control on the ventilatory threshold in adults with non-insulin dependent diabetes mellitus. Diabetes Research $\mathbf{2 5}$, $39-46$.

Ebbeling C, Ward A \& Rippe J (1988) Evaluation of the ACSM energy cost for walking. Journal of Cardiorespiratory Rehabilitation 8, 400.

Epstein LH \& Wing RR (1980) Aerobic exercise and weight. Addictive Behaviors 5, 371-388.
Eston R \& Connolly D (1996) The use of ratings of perceived exertion for exercise prescription in patients receiving betablocker therapy. Sports Medicine 21, 176-190.

Evans SL, Davy KP, Stevenson ET \& Seals DR (1995) Physiological determinants of $10-\mathrm{km}$ performance in highly trained female runners of different ages. Journal of Applied Physiology 78, 1931-1941.

Feigenbaum MS \& Pollock ML (1997) Strength trainingrationale for current guidelines for adult fitness. Physician and Sports Medicine 25, 44.

Fletcher GF, Balady G, Froelicher VF, Hartley LH, Haskell WL \& Pollock ML (1995) Exercise standards: A statement for healthcare professionals from the American Heart Association. Circulation 91, 580-615.

Foreyt JP, Brunner RL, Goodrich GK, St Jeor ST \& Miller GD (1995) Psychological correlates of reported physical activity in normal-weight and obese adults: the Reno diet-heart study. International Journal of Obesity 17, 279-286.

Francis K \& Hoobler T (1986) Changes in oxygen consumption associated with treadmill walking and running with light handcarried weights. Ergonomics 29, 999-1004.

Frey-Hewitt B, Vranizan KM, Dreon DM \& Wood PD (1990) The effect of weight loss by dieting or exercise on resting metabolic rate in overweight men. International Journal of Obesity $\mathbf{1 4}$, 327-334.

Friedberg SJ, Harlan WR \& Estes EH (1960) The effects of exercise on the concentration and turnover of plasma nonesterified fatty acids. Journal of Clinical Investigation 39. 215-220.

Glass SC, Whaley MH \& Wegner MS (1991) Rating of perceived exertion among standard treadmill protocols and steady state running. International Joumal of Sports Medicine 12, 7782.

Goldberg GR, Prentice AM, Davies HL \& Murgatroyd PR (1990) Residual effect of gradual levels of exercise on metabolic rate. European Journal of Clinical Nutrition 44, 99-105.

Graves JE, Martin AD, Miltenberger LA \& Pollock ML (1988) Physiological responses to walking with hand weights, wrist weights, and ankle weights. Medicine and Science in Sports and Exercise 20, 265-271.

Graves JE, Pollock ML, Montain SJ, Jackson AS \& O'Keefe JM (1987) The effect of hand-held weights on the physiological responses to walking exercise. Medicine and Science in Sports and Exercise 19, 260-265.

Grediagin A, Cody M, Rupp J, Benardot D \& Shern R (1995) Exercise intensity does not effect body composition change in untrained and moderately overfat women. Journal of the American Dietetic Association 95, 661-665.

Haskell WL (1984) The influence of exercise on the concentrations of triglyceride and cholesterol in human plasma. Exercise and Sport Sciences Reviews 12, 205-244.

Haskell WL (1994) Health consequences of physical activity: understanding and challenges regarding dose-response. Medicine and Science in Sports and Exercise 26, 649-660.

Havel RJ, Pernow B \& Jones NL (1967) Uptake and release of fatty acids and other substrates in the legs of exercising men. Journal of Applied Physiology 23, 90-99.

Henriksson J (1977) Training induced adaptation of skeletal muscle and metabolism during submaximal exercise. Journal of Physiology 270, 661-675.

Hetzler RK, Seip RL, Pierce E, Snead D \& Waltman A (1991) Effect of exercise modality on ratings of perceived exertion at various lactate concentrations. Medicine and Science in Sports and Exercise 23, 88-89.

Hill JO, Drougas H \& Peters JC (1993) Obesity treatment: can diet composition play a role? American College of Physicians 119, 694-697. 
Hill JO, Melby C, Johnson SL \& Peters JC (1995) Physical activity and energy requirements. American Journal of Clinical Nutrition 62, S1059-S1066.

Hills AP \& Wahlqvist ML (editors) (1994) What is overfatness? In Exercise and Obesity, pp. 1-6. London: Smith-Gordon.

Holloszy JO \& Coyle EF (1983) Adaptations of skeletal muscle to endurance exercise and their metabolic consequences. Journal of Applied Physiology 56, 831-838.

Hurley BF, Nemeth PM, Martin WH, Hagberg JM, Dalsky GP \& Holloszy JO (1986) Muscle triglyceride utilization during exercise: effect of training. Journal of Applied Physiology 60, $562-567$

Jakicic JM, Donnelly JE, Pronk NP, Jawad AF \& Jacobsen DJ (1995) Prescription of exercise intensity for the obese patient: the relationship between $\mathrm{hr}, \mathrm{V}_{\mathrm{O}_{2}}$ and perceived exertion. International Journal of Obesity 19, 382-387.

James WPT (1995) A public health approach to the problem of obesity. International Journal of Obesity 19, S37-S45.

Jebb S \& Prentice A (1995) Is obesity an eating disorder? Proceedings of the Nutrition Society 54, 721-728.

Jette $M$ (1975) An exercise prescription program for use in conjunction with the Canadian Home Fitness Test. Canadian Journal of Public Health 66, 461-464.

Katz MZ \& Lowenthal DT (1994) Influences of age and exercise on glucose metabolism: implications for management of older diabetics. Southern Medical Journal 87, S70-S73.

Keren G, Epstein Y, Magazanik A \& Sohar E (1981) The energy cost of walking and running with and without a backpack load. European Journal of Applied Physiology 46, 317-324.

Lee L, Kumar S \& Leong LC (1994) The impact of a five-month basic military training on the body weight and body fat of 197 moderately to severely obese Singaporean males age 17 to 19 years. International Journal of Obesity 18, 105-109.

Leutholtz BC, Keyser RE, Heusner WW, Wendt VE \& Rosen L (1995) Exercise training and severe caloric restriction: effect on lean body mass in the obese. Archives of Physical Medicine and Rehabilitation 76, 65-70.

McArdle WD, Katch FI \& Katch VL (1996) Exercise Physiology, 4th ed. Baltimore, MD: Williams \& Wilkins.

Makalous SL, Araujo J \& Thomas TR (1988) Energy expenditure during walking with hand weights. Physician and Sports Medicine 16, 139-148.

Martin WH (1996) Effects of acute and chronic exercise on fat metabolism. Exercise and Sport Sciences Reviews 24, 203-231.

Milesis CA, Pollock ML, Bah MD, Ayres JJ, Ward A \& Linnerud AC (1976) Effects of different durations of physical training on cardio-respiratory function, body composition, and serum lipids. Research Quarterly 47, 716-725.

Miller WC, Wallace JP \& Eggert KE (1993) Predicting max HR and the HR-VO2 relationship for exercise prescription in obesity. Medicine and Science in Sports and Exercise 25, 1077-1081.

National Health \& Medical Research Council (1997) Acting on Australia's Weight: a Strategic Plan for the Prevention of Overweight and Obesity. Canberra: Australian Government Publishing Service.

Noble B, Borg G, Jacobs I, Ceci R \& Kaiser P (1983) A categoryratio perceived exertion scale: relationship to blood and muscle lactates and heart rate. Medicine and Science in Sports and Exercise 15, 523-528.

O'Hara WJ, Allen C \& Shephard RJ (1977) Treatment of obesity by exercise in the cold. Canadian Medical Association Journal 117, 773-786.

O'Hara WJ, Allen C, Shephard RJ \& Allen G (1979) Fat loss in the cold - a controlled study. Journal of Applied Physiology 46, 872-877.

Oscai LB (1973) The role of exercise in weight control. Exercise and Sport Sciences Reviews 1, 103-123.
Paffenbarger RS, Wing AL, Hyde RT \& Jung DL (1983) Physical activity and incidence of hypertension in college alumni. American Journal of Epidemiology 117, 245-257.

Pandolf KB \& Goldman RF (1975) Physical conditioning of less fit adults by use of leg weight loading. Archives of Physical and Medical Rehabilitation 56, 255-261.

Pate RR (1995) Physical activity and health: dose-response issues. Research Quarterly 66, 313-317.

Poehlman ET (1989) A review: exercise and its influence on resting energy metabolism in man. Medicine and Science in Sports and Exercise 21, 515-525.

Poehlman ET, Melby CL \& Goran MI (1991) The impact of exercise and diet restriction on daily energy expenditure. Sports Medicine 11, 78-101.

Pollock ML, Fiegenbaum MS \& Brechue WF (1995) Exercise prescription for physical fitness. Quest 47, 320-337.

Pollock ML, Graves JE, Swart DL \& Lowenthal DT (1994) Exercise training and prescription for the elderly. Southern Journal of Medicine 87, S88-S95.

Pollock ML \& Jackson A (1977) Body composition: measurement and changes resulting from physical training. In Toward an Understanding of Human Performance, pp. 67-77 [E] Burke, editor]. Ithaca, NY: Mouvement Publications.

Pollock ML, Miller HS Jr, Linnerud AC \& Cooper KH (1975) Frequency of training as a determinant for improvement in cardiovascular function and body composition of middle aged men. Archives of Physical Medicine Rehabilitation 56, 141145.

Pollock ML, Ward A \& Ayres JJ (1977) Cardiorespiratory fitness: responses to differing intensities and durations of training. Archives of Physical Medicine and Rehabilitation 58, 467-473.

Pollock ML \& Wilmore J (1990) Exercise in Health and Disease: Evaluation and Prescription for Prevention and Rehabilitation, 2nd ed. Philadelphia, PA: Saunders.

Porcari J, McCarron R, Kline G, Freedson PS \& Ward A (1987) Is fast walking an adequate aerobic training stimulus for 30- to 60 year-old men and women? Physician and Sports Medicine 15, 119-129.

Porcari JP, Ebbeling CB, Ward A, Freedson PS \& Rippe JM (1989a) Walking for exercise testing and training. Sports Medicine 8, 189-200.

Porcari JP, Ward A, Morris D, Maher M \& Cuneo P (1989b) Comparison of weight loss in males and females after 16 weeks of fitness walking and/or diet. Medicine and Science in Sports and Exercise 21, S201.

Powers SK \& Howley ET (1997) Exercise Physiology: Theory and Application to Fitness and Performance, 3rd ed. Madison, WI: Brown \& Benchmark.

Prentice AM \& Jebb SA (1995) Obesity in Britain: gluttony or sloth? British Medical Journal 311, 437-439.

Ravussin E, Lilloja S, Knowler WC, Christian L, Freymond D, Abbott WG, Boyce V, Howard BV \& Bogardus C (1988) Reduced rate of energy expenditure as a risk factor for body weight gain. New England Journal of Medicine 318 , $467-472$.

Ravussin E \& Tataranni PA (1996) The role of altered sympathetic nervous system activity in the pathogenesis of obesity. Proceedings of the Nutrition Society 55, 793-802.

Rising R, Harper IT, Fontvielle AM, Ferraro RT, Spraul M \& Ravussin E (1994) Determinants of total daily energy expenditure: variability in physical activity. American Journal of Clinical Nutrition 59, 800-804.

Ritchie SE \& Hopkins WG (1991) The intensity of exercise in deep-water running. International Journal of Sports Medicine 12, 27-29.

Riviere D, Crampes F, Beauville M \& Garrigues M (1989) Lipolytic response of fat cells to catecholamines in sedentary 
and exercise-trained women. Journal of Applied Physiology 66, 330-335.

Robertson RJ, Casperson CJ, Allison TG, Skrinar GS \& Abbott RA (1982) Differentiated perceptions of exertion and energy cost of young women while carrying loads. European Journal of Applied Physiology 49, 69-78.

Romijn JA, Coyle EF, Sidossis LS, Gastaldelli A, Horowitz JF, Endert E \& Wolfe RR (1993) Regulation of endogenous fat and carbohydrate metabolism in relation to exercise intensity and duration. American Journal of Physiology 265, E380-E391.

Saltzman E \& Roberts SB (1995) The role of energy expenditure in energy regulation: findings from a decade of research. Nutrition Reviews 53, 209-222.

Sandvik L, Erikssen J, Thaulow E, Erikssen G, Mundal R \& Rodahl K (1993) Physical fitness as a predictor of mortality among healthy, middle aged Norwegian men. New England Journal of Medicine 328, 533-537.

Saris WHM (1996) Physical inactivity and metabolic factors as predictors of weight gain. Nutrition Reviews 11, S110S115.

Schultz LO \& Schoeller DA (1994) A compilation of total daily energy expenditures and body weight in healthy adults. American Journal of Clinical Nutrition 60, 676-681.

Schwartz RS, Shuman WP \& Larson V (1991) The effect of intensive endurance training on body fat distribution in young and older men. Metabolism 40, 545-551.

Seip RL, Snead D, Pierce EF \& Weltman A (1991) Perceptual responses and blood lactate concentration: effect of training state. Medicine and Science in Sports and Exercise 23, 80-87.

Shah M \& Jeffery RW (1991) Is obesity due to overeating and inactivity, or to a defective metabolic rate? A review. Annals of Behavioral Medicine 13, 73-81.

Sheldahl LM (1985) Special ergometric techniques and weight reduction. American Journal of Clinical Nutrition 18, 25-30.

Sheldahl LM, Buskirk JL, Loomis JL, Hodgson JL \& Mendez J (1982) Effects of exercise in cool water on body weight loss. International Journal of Obesity 6, 29-42.

Soukup JT \& Kovaleski JE (1993) A review of the effects of resistance training for individuals with diabetes mellitus. Diabetes Educator 19, 307-312.

Stefanick ML (1993) Exercise and weight control. Exercise and Sport Sciences Reviews 21, 363-396.

Svedenhag J \& Seger J (1992) Running on land and in water: comparative exercise physiology. Medicine and Science in Sports and Exercise 24, 1155-1160.

Tanaka K, Takeshima N, Kato T, Nihata S \& Ueda K (1990) Critical determinants of endurance performance in middle aged and elderly endurance runners with heterogeneous training habits. European Journal of Applied Physiology and Occupational Physiology 59, 443-449.

Thompson JL, Manore MM \& Thomas JR (1996) Effects of diet and diet-plus-exercise programs on resting metabolic rate: a meta-analysis. International Journal of Sports Nutrition 6, 4161.

Tremblay A, Despres JP, Leblanc C, Craig CL, Ferris B, Stephens T \& Bouchard C (1990) Effect of physical activity on body fatness and fat distribution. American Journal of Clinical Nutrition 51, 153-157.
Tremblay A, Nadeau A, Despres JP \& St-Jean L (1990) Longterm exercise training with constant energy intake. 2: Effect on glucose metabolism and resting energy expenditure. International Journal of Obesity 14, 75-84.

Tremblay A, Simoneau JA \& Bouchard C (1994) Impact of exercise intensity on body fatness and skeletal muscle metabolism. Metabolism 43, 814-818.

US Department of Health and Human Services (1996) Physical Activity and Health: A Report of the Surgeon General. Atlanta, GA: Department of Health and Human Services, Centers for Disease Control and Prevention, National Center for Chronic Disease Prevention and Health Promotion.

Van Zant RS (1992) Influence of diet and exercise on energy expenditure - a review. International Journal of Sports Medicine 2, 1-19.

Voloshin AS (1988) Shock absorption during walking and running. Journal of the Podiatric Medical Association 78, 295-299.

Vroman NB, Buskirk ER \& Hodgson JL (1983) Cardiac output and skin blood flow in lean and obese individuals during exercise in the heat. Journal of Applied Physiology 55, 69-74.

Walcott G, Coleman R, MacVeigh M, Ross J \& Gurry M (1986) Heart rate and VO2max response to weighted walking. Medicine and Science in Sports and Exercise 18, S28.

Weltman A (1995) The Blood Lactate Response. Current Issues in Exercise Science Monograph no. 4. Champaign, IL: Human Kinetics.

Wibom R, Hultman E, Johansson M, Matherei K, ConstantinTeodosiu D \& Schantz PG (1992) Adaptation of mitochondrial ATP production in human skeletal muscle to endurance training and detraining. Journal of Applied Physiology 73, 2004-2010.

Wilber RL, Moffatt RJ, Scott BE, Lee DT \& Cucuzzo NA (1996) Influence of water run training on the maintenance of aerobic performance. Medicine and Science in Sports and Exercise $\mathbf{2 8}$, 1056-1062.

Williams JG \& Eston RG (1989) Determination of the intensity dimension in vigorous exercise programmes with particular reference to the use of the rating of perceived exertion. Sports Medicine 8, 177-189.

Williamson DF, Kahn HS, Remington PL \& Anda RF (1993) The 10-year incidence of overweight and major weight gain in US adults. Archives of International Mediciine 150, 665-672.

Wilmore JH \& Costill DL (1994) Physiology of Sport and Exercise, pp. 504-505. Champaign, IL: Human Kinetics.

Wing RR, Matthews KA, Kuller LH, Meilahn EN \& Plantinga P (1991) Waist to hip ratio in middle-aged women. Associations with behavioral and psychosocial factors and with changes in cardiovascular risk factors. Arteriosclerosis Thrombosis 11, 1250-1257.

Wolfe RR, Klein S, Carraro F \& Weber JM (1990) Role of triglyceride-fatty acid cycle in controlling fat metabolism in humans during and after exercise. American Joumal of Physiology 258, E382-E389.

Zelasko CJ (1995) Exercise for weight loss: what are the facts? Journal of the American Dietetic Association 95, 1414 1417.

Zierler KL (1976) Fatty acids as substrates for heart and skeletal muscle. Circulation Research 38, 459-463. 